
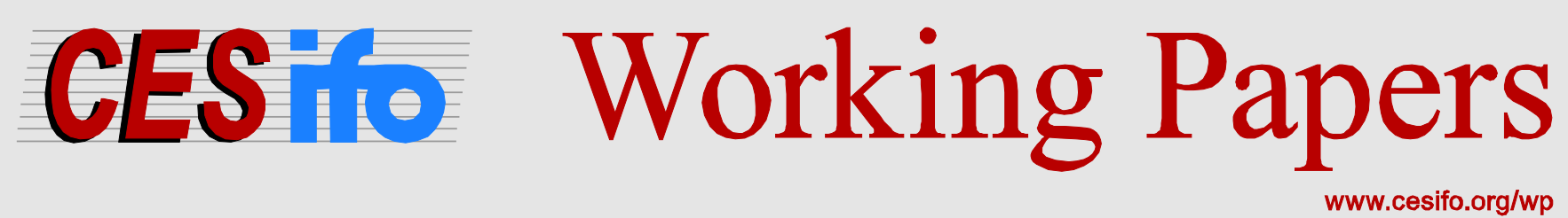

\title{
Sovereign Default Risk and Banks in a Monetary Union
}

\author{
Harald Uhlig
}

\section{CESIFO WORKING PAPER NO. 4368 \\ CATEgORY 7: MONETARy POLICY AND INTERNATIONAL FinANCE \\ August 2013}
An electronic version of the paper may be downloaded
- from the SSRN website: Www.SSRN.com
- from the RePEc website: Www.RePEc.org
- from the CESifo website: www.CESifo-group.org/wp

\section{CESifo}




\title{
Sovereign Default Risk and Banks in a Monetary Union
}

\begin{abstract}
This paper seeks to understand the interplay between banks, bank regulation, sovereign default risk and central bank guarantees in a monetary union. I assume that banks can use sovereign bonds for repurchase agreements with a common central bank, and that their sovereign partially backs up any losses, should the banks not be able to repurchase the bonds. I argue that regulators in risky countries have an incentive to allow their banks to hold home risky bonds and risk defaults, while regulators in other "safe" countries will impose tighter regulation. As a result, governments in risky countries get to borrow more cheaply, effectively shifting the risk of some of the potential sovereign default losses on the common central bank.

JEL-Code: E510, E580, E610, E620, E650, G210, G280, H630.

Keywords: Euro zone crisis, sovereign default risk, bank regulation, risk shifting, common central bank, European Central Bank, ECB, repurchase operations, haircuts.
\end{abstract}

\author{
Harald Uhlig \\ Department of Economics \\ University of Chicago \\ 116 East $59^{\text {th }}$ Street \\ USA - Chicago, IL 60637 \\ huhlig@uchicago.edu
}

This revision: August 12, 2013

I am grateful to Thorsten Drautzburg for excellent research assistance. This research has been supported by the NSF grant SES-0922550 and by a Wim Duisenberg fellowship at the ECB. I have an ongoing consulting relationship with a Federal Reserve Bank, the Bundesbank and the ECB. The views here are entirely my own. 


\section{Introduction}

The European Monetary Union is in distress. Mechanisms that were meant to safe-guard key institutions and to assure stability have become sources of balance sheet risk for these very institutions. Liquidity provision within the European Monetary Union rests upon repurchase agreements, by which banks guarantee the repurchase of assets deposited with the European Central Bank. If either the bank fails or the asset fails, but not both, this mechanism safe-guards the repayment to the ECB, since it can either rely on the repurchase by the bank or sell the asset. However, when both fail as well as the bank home country fails, the ECB incurs a loss.

One symptom of these developments are the dramatic increases in Target 2 imbalances, as extensively documented and discussed by Sinn (2012). Indeed, banks in troubled Euro zone countries appear to concentrate their portfolio of government bonds particularly on the bonds of their own country, rather than seeking safety by holding bonds of other countries, see figure 1 . This behavior appears to be encouraged or at least positively tolerated by the regulators in these countries, who may assert that purchases of the bonds of their countries by their own banks is necessary in order to be able to finance the government at all, thereby endangering the safety of their banks down the road in the case of a sovereign default.

This paper is motivated by these developments. It seeks to understand the underlying forces and incentives more deeply. It seeks to understand the interplay between banks, bank regulation, sovereign default risk and central bank guarantees in a monetary union. I assume that banks can use sovereign bonds for repurchase agreements with a common central bank, and that their sovereign partially backs up any losses, should the banks not be able to repurchase the bonds. I argue that regulators in risky countries have an incentive to allow their banks to hold home risky bonds and risk defaults, while reg- 


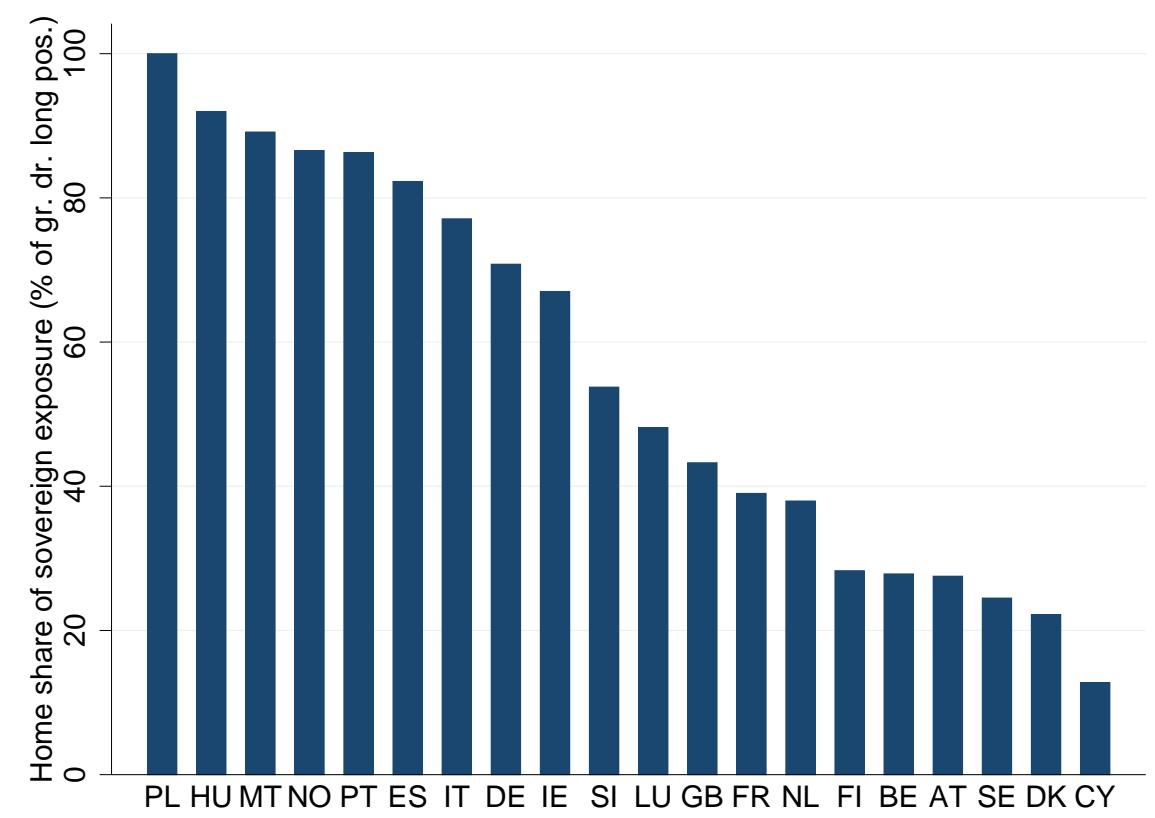

Figure 1: This graph uses data from the European bank stress test in 2011 to show the fraction of sovereign debt held in the form of domestic sovereign debt, aggregating across the banks in the data sample in each country. Country key: PL Poland, HU Hungary, MT Malta, NO Norway, PT Portugal, ES Spain, IT Italy, DE Germany, IE Ireland, SI Slovenia, LU Luxembourg, GB United Kingdom, FR France, NL Netherlands, FI Finland, BE Belgium, AT Austria, SE Sweden, DK Denmark, CY Cyprus. 
ulators in other "safe" countries will impose tighter regulation. As a result, governments in risky countries get to borrow more cheaply, effectively shifting the risk of some of the potential sovereign default losses on the common central bank. As a result, the monetary union has become a system engineered to deliver underpriced loans from country banks to their sovereigns, and to implicitly shift sovereign default risk onto the balance sheet of the ECB and the rest of the Eurosystem.

In the model, banks pursue their investment strategy voluntarily: it is up to regulators to potentially constrain them. Other explanations are conceivable, of course. Useful, general perspectives on financial crises and government regulations are Reinhart (2012a) as well as Claessens and Kose (2013). A prominent alternative argument for why banks hold bonds of their home country is "financial repression", see Reinhart (2012b), i.e. regulators make them hold the sovereign bonds, perhaps with strong-arm tactics, perhaps in exchange for "looking the other way" concerning weak portfolios of commercial loans and mortgages, or simply as a "favor" in a long, ongoing relationship. Since the banks could potentially refuse, though at considerable cost, it still must ultimately be preferable to them to hold own-country bonds rather than invest elsewhere or to close: so, in some ways, this paper may also be understood as a model of financial repression. A further alternative is a political economy argument: if sovereign bonds are held by home banks, it makes it politically harder to default on these bonds, as this will hurt domestic banks and savers. If so, then such a portfolio arrangement might serve as a commitment device for the government in trouble. While this is an interesting angle, this paper will be silent on this perspective.

The issue of sovereign default risk, bank portfolios and the role of the central bank has received considerable attention in the recent literature. Acharya and Steffen (2013) is a careful empirical analysis of the "carry trade" by banks, which fund themselves in the wholesale market and invest in risky 
sovereign bonds. They document, that "over time, there is an increase in 'home bias' - greater exposure of domestic banks to its sovereigns bonds which is partly explained by the European Central Bank funding of these positions," providing an in-depth analysis of the facts indicated in figure 1 as well as solid empirical support for the theory provided below. Relatedly, Corradin and Rodriguez-Moreno (2013) show that USD-denominated sovereign bonds of Euro zone countries became substantially cheaper (i.e., delivering a higher yield) than Euro-denominated bonds during the Euro zone crisis, and ascribe it to the usefulness to banks of Euro-denominated bonds as collateral vis-a-vis the ECB, while USD-denominated bonds do not offer this advantage. Again, this supports the perspective in this paper. Drechsler et. al. (2013) document "a strong divergence among banks' take-up of" Lender-ofLast-Resort assistance "during the financial crisis in the euro area, as banks which borrowed heavily also used increasingly risky collateral". They test several hypothesis and argue that their "results strongly support the riskshifting explanation", in line with the theory below.

Like this paper, Broner et al. (2013) is motivated by the shift towards home sovereign debt during the Euro crisis. Their analysis is somewhat parallel to my model here, as they also show that "sovereign debt offers a higher expected return to domestic creditors than to foreign ones". There are considerable difference in the modeling details, however. Roch and Uhlig (2012) analyze the role of actuarily fair bailouts to resolve multiple-equilibriumdriven sovereign default crises, thus shedding light on the OMT program of the ECB. There is considerably more, but let me stop here. 


\section{$2 \quad$ A model}

\subsection{The actors and their interaction}

There are three periods, $t=0,1,2$. There is a monetary union of many countries and a common central bank. One "small" country will be considered risky, while all other countries will be considered "safe": we shall thus only distinguish between the risky country and the rest of the monetary union. All units are in terms of the common currency. I shall abstract from the issue of inflation, which does not appear to be central at this juncture in the European Monetary Union, though it may well be so in the future. I therefore assume that a unit of the currency can be be used to purchase a unit of the consumption good in any given period, i.e., all the accounting could alternatively be done in terms of a numeraire consumption good.

1. There is a continuum of banks $j \in[0,1]$ in each country with initial net worth $^{1} n>0$. Therefore, $n$ also denotes the total net worth available per country. The banks are each owned by a banker or bank owner, who maximizes expected consumption in period 2. Their consumption must be nonnegative. I will use the word "bank" and "banker" interchangeably, but one may wish to think of the bank being regulated and carrying out investment strategies, while the bank owner or banker cares about the result.

2. There is large population of households in each country, holding in total a deposit of 1 unit with each bank at the beginning of period 0 . Households withdraw their deposits in period 1.

3. In each country, there is a government, which has a spending need $g_{0}$ in period 0 , and otherwise seeks to maximize expected government

\footnotetext{
${ }^{1}$ This can be interpreted as net worth inclusive of long-term deposits, which will not be withdrawn
} 
spending in period 2. Each government is endowed with resources in period 2. I assume that all governments except one are "safe", i.e. always have sufficiently large resources in all periods, including period 2. There is one "risky" government (or one government in a "risky" country), which has resources $y \sim G$ in period $2, y \geq 0$ and $P(y>0)>0$. I assume that

$$
E[y]>g_{0}
$$

Governments issue bonds in period 0 to finance their spending need, with the promise to repay them in period 2. The budget constraint of the risky government in period 0 is therefore

$$
q B=g_{0}
$$

where $B$ is the total outstanding face value of its debt and $q$ is the market price per unit of the bond. The governments regulate the asset positions of banks in period 0 , by imposing an upper bound $\bar{b}$ with

$$
\bar{b} \leq \frac{1+n}{q}
$$

on their holding of risky bonds in period 0 . Note that the same bound is imposed on all banks, by assumption ${ }^{2}$. Furthermore, the governments are nominally obliged to pay for a share $0<\alpha \leq 1$ of the losses of their banks in period 2, but will fractionally default on this obligation, if they lack the funds to do so. The regulators will impose the bounds on the bond positions optimally in order to maximize expected period-2

\footnotetext{
${ }^{2}$ One can easily generalize this model to the situation, where deposits as well as $\bar{b}$ is proportional to $n$ : for that reason, we shall often use a notation, expressing everything in proportion to $n$. It is considerably more challenging to allow heterogeneity in $n$ as well as in the regulatory bounds. The assumption of homogeneity can be motivated by the general legal principle, that the law should treat all market participants equitably.
} 
government consumption, and choose the most liberal regulation among all those achieving this maximum.

4. There is a common central bank. The central bank can issue cash and engage in repurchase agreements with the banks. Any shortfalls in period 2 are paid for by the governments in period 2: in equal proportions, up to the resources available to each government.

I assume that these players interact as follows. The interactions place considerable restrictions on the available contracts: these restrictions shall be examined further below.

In period 0 , the households place 1 unit of deposits at the beginning of period 0 with each bank: thus, $1 / n$ can be understood as the leverage ratio of bank $j$ in a country. Banks use their net worth and the deposited resources to buy a portfolio of bonds from the countries, subject to regulatory restrictions imposed by their respective governments. More specifically, they buy bonds $b \geq 0$ at price $q$ from the "risky" government, where $b$ is the face value ("promise to pay in period 2") of the bonds. They use the remainder of the funds to buy safe bonds, which are assumed to be like cash: thus, their price is unity, and their quantity shall be denoted by $m \geq 0$. Taking into account the regulatory constraint, the budget constraint of a bank is

$$
q b+m=1+n, b \leq \bar{b}, b \geq 0, m \geq 0 .
$$

In period 1, households withdraw their deposits ${ }^{3}$. In order to meet these liquidity needs, banks first sells safe bonds $\tilde{m}$, until they reach $\tilde{m}=m$, and then approach the common central bank for a repurchase contract for the remainder. In the repurchase contract, the bank sells $\tilde{b} \geq 0$ bonds to the

\footnotetext{
${ }^{3}$ This is motivated by the large withdrawals of depositors at banks in the south of the EMU in recent years. While the withdrawal is "hardwired" here and assumed to be total, a more complete model might endogenize these withdrawal decisions.
} 
central bank at price $\phi q$, where $0<\phi \leq 1$ represents a hair cut applied by the central bank, with the agreement of repurchasing them at the same price in period 2. I assume that the hair cut parameter $\phi$ is common across all banks. Thus, in period 1 , a bank with portfolio $(b, m)$ faces the budget constraint

$$
\phi q \tilde{b}+\tilde{m}=1, \tilde{m}=\min \{m, 1\} .
$$

For the analysis here, I assume that the central bank chooses the common hair cut parameter $\phi$ in period 1, so that this constraint is always satisfied: otherwise, banks would need to default on their withdrawing households. This captures the impression that, up to 2013, the ESCB has largely provided liquidity to banks in affected countries, when needed.

In period 2, the bonds mature. The safe bonds ("cash $m$ ") pay one unit per bond. The risky bonds pay $0 \leq \theta \leq 1$ per unit of face value, with $\theta<1$ representing a default by the risky government. If a bank has entered a repo agreement with the central bank, it will purchase back as many of the bonds sold to the central bank in period 0 at the agreed-upon price $\phi q$ per unit as possible, making use of its own resources as well as the maturing payments on the bonds it is repurchasing from the central bank. If the repurchase is not done in full, the bank is considered in default: the ensuing losses are then split between the central bank and the government of that bank, with the government bearing a share $0 \leq \theta \alpha \leq 1$ of these $\operatorname{losses}^{4}$ and the central bank bearing the remaining fraction $1-\theta \alpha$ of the losses. If the repurchase is done in full, the banks keep the excess resources and consume. Governments must first repay bonds and pay for their share of losses at their banks, before consuming the remainder $g_{2}$, with $\alpha$ a parameter of the model, and $\theta$ emerging endogenously from the budget constraint of the government

$$
g_{2}+\theta(B+\alpha L)=y, 0 \leq \theta \leq 1, g_{2} \geq 0 \text { and } g_{2}=0 \text { if } \theta<1,
$$

\footnotetext{
${ }^{4}$ Note that I assume that the government defaults on its obligations to "recapitalize" its banks at the same rate $\theta$ that it defaults on its bond repayments.
} 
where $B$ is the total face value of bonds issued in period 0 and where $L$ are the total losses in their banks.

\subsection{Analysis}

Consider first the problem of a bank $j$, after purchase of the portfolio $(b, m)$ per the budget constraint (3). Given the survival in period 1, as assumed, and the liabilities to the central bank in period 2 , and substituting for $m$ per (3), the banker owning this bank will enjoy period-2 consumption, written as a function of the value of the investment $q b$,

$$
\begin{aligned}
c(q b) & =\max \{\theta b+m-1 ; 0\} \\
& =\max \left\{\left(\frac{\theta}{q}-1\right) \frac{q b}{n}+1 ; 0\right\} n
\end{aligned}
$$

and produce losses of

$$
\begin{aligned}
l(q b) & =\max \{1-\theta b-m ; 0\} \\
& =\max \left\{\left(1-\frac{\theta}{q}\right) \frac{q b}{n}-1 ; 0\right\} n .
\end{aligned}
$$

Define

$$
\beta=\min \left\{\frac{q \bar{b}}{n}, \frac{1+n}{n}\right\}
$$

Notice that $0 \leq q b \leq \beta n$, with the first entry denoting the regulatory bound and the second entry arising from $m \geq 0$. Therefore, if the banker invests the maximum amount possible in bonds (or, more precisely, instructs his bank to invest the maximum amount possible in bonds), he will receive expected consumption

$$
E[c(\beta n)]=\chi(\beta) n,
$$

where

$$
\chi(\beta)=E\left[\max \left\{\left(\frac{\theta}{q}-1\right) \beta+1 ; 0\right\} .\right.
$$


If the banker instructs his bank to invest only in cash, he will receive expected consumption equal to $n$.

Proposition 1 The results do not depend on the haircut parameter $\phi$.

Proof: None of the expressions above depends on $\phi$.

This may be a bit surprising, since it is often argued that by some appropriate haircut, the central bank can insulate itself against losses. The haircut parameter does not matter here, and therefore, it will not matter below either.

Proposition 2 - If $1<\chi(\beta)$ the banker will invest the maximum amount possible in bonds, $b=\beta n$.

- If $1>\chi(\beta)$, the banker will only hold cash.

- If $1=\chi(\beta)$, the banker is indifferent between "all cash" and "all bonds" and

- strictly prefers this to any interior solution, if $P\left(\left(\frac{\theta}{q}-1\right) \beta+1<\right.$ 0) $>0$.

- is indifferent between all feasible portfolio allocations, if $P\left(\left(\frac{\theta}{q}-1\right) \beta+\right.$ $1<0)=0$.

Furthermore, $\chi$ is a convex function of $\beta$, with

$$
\chi(\beta) \geq\left(\frac{E[\theta]}{q}-1\right) \beta+1,
$$

and the inequality is strict, if $P\left(\left(\frac{\theta}{q}-1\right) \beta+1<0\right)>0$.

Proof: Note that $c(b)$ is a convex function of $b$, that $E[c(b)]$ is a strictly convex function of $b$, if $P\left(\left(\frac{\theta}{q}-1\right) \beta+1<0\right)>0$, and that $E[c(b)]$ is a linear 
function of $b$ in the feasible range, if $P\left(\left(\frac{\theta}{q}-1\right) \beta+1<0\right)=0$. Equation (9) follows from dropping the "max" operator in the definition of $\chi$.

\section{Proposition 3}

$$
0 \leq q \leq 1
$$

Proof: $q \geq 0$ is clear. As for $q \leq 1$, note that $\theta \leq 1$. Therefore, at $q>1$,

$$
\left(\frac{\theta}{q}-1\right) \beta+1<1
$$

and thus, $\chi(q)<1$. Per proposition 2, no banker would hold the risky bonds at $q>1$, in contradiction to market clearing for the risky bonds.

Next, consider the problem facing regulators in safe countries. Given the distribution for default rates $\theta$, let

$$
\underline{\theta}=\sup \{\tilde{\theta} \mid P(\theta \geq \tilde{\theta})=1\}
$$

be the probabilistically smallest value for $\theta$.

Proposition 4 If $q \leq \underline{\theta}$, regulators in the safe countries will not impose any regulatory bounds. If $q>\underline{\theta}$, regulators in safe countries will impose

$$
\bar{b}^{\text {safe }}(n)=\frac{1}{q-\underline{\theta}} n,
$$

and thus assure that banks will avoid losses, with probability 1,

$$
P\left(\left(\frac{\theta}{q}-1\right) \beta^{\text {safe }}+1<0\right)=0 .
$$

Banks in safe countries will purchase risky bonds, if and only if

$$
q \leq E[\theta]
$$


with indifference between cash and bonds, in case of "=". I.e., these banks only purchase risky bonds, if their price is less than or at most equal to the actuarily fair value.

Proof: This follows from the assumption that regulators maximize expected government consumption in period 2, and seek the most liberal portfolio regulation that achieves that. Since banks never make losses,

$$
\chi(\beta)=\left(\frac{E[\theta]}{q}-1\right) \min \left\{\frac{q}{q-\underline{\theta}}, \frac{1+n}{n}\right\}+1 .
$$

Therefore, $1 \leq \chi(\beta)$ is equivalent to (12).

As an immediate consequence, we have

\section{Proposition 5}

$$
q \geq E[\theta] .
$$

Furthermore, if $\theta$ is not constant almost surely, then $P(\theta<q)>0$ and regulators in safe countries will impose the constraint (11).

Proof: The resources of the safe country banks are assumed large compared to the financing need of the risky country.

Therefore, from here on forward, we shall only refer to the risky country, when discussing the regulatory bound $\bar{b}$ as well as

$$
\beta=\min \left\{\frac{q \bar{b}}{n}, \frac{1+n}{n}\right\} .
$$

Proposition 6 If the initial financing needs of the risky country exceed the (regulated) resources of its own banks, $g_{0}>\beta n$, then $q=E[\theta]$. Furthermore, at $q=E[\theta]$, the banks in the risky country are either indifferent between cash and bonds, or strictly prefer to hold bonds. 
Proof: This is a consequence of the analysis above. Note, for example, that (9) implies $\chi(\beta) \geq 1$ at $q=E[\theta]$, regardless of $\beta \geq 0$. Proposition (2) therefore delivers the claim regarding the banks in the risky country.

Therefore, if $q=E[\theta]$ and $\chi(\beta)=1$ for banks in the risky country, the banks in the risky country might choose cash. But in that case, the regulators in the risky country might have already set $\bar{b}=0$ in the first place. Without loss of generality, we can therefore analyze the regulatory problem of the risky country as the problem of setting the bound $\bar{b}$, and assume that the banks in the risky country always hold the maximum amount of bonds allowed, provided the attractiveness condition

$$
1 \leq \chi(\beta)
$$

is satisfied, see proposition 2. If all bonds are sold to banks in the risky country (which obviously requires $g_{0} \leq n+1$ ), then

$$
g_{0}=\beta n
$$

is the market clearing condition. In that case, $\bar{b}$ implies the market price $q$ per

$$
q=\frac{g_{0}}{\bar{b}}
$$

and satisfies

$$
q \leq E[\theta]
$$

If some bonds are sold to safe countries, then

$$
q=E[\theta]
$$

and

$$
\beta<\frac{g_{0}}{n} .
$$


The distribution for $\theta$ arises from taking into account the losses of risky country banks, at their maximum bond leverage $\beta$. They are

$$
\begin{aligned}
L(\beta) & =\max \left\{\left(1-\frac{\theta}{q}\right) \beta-1 ; 0\right\} n \\
& \leq \max \left\{\left(1-\frac{\theta}{q}\right) g_{0}-n ; 0\right\}
\end{aligned}
$$

with equality in the second line if all bonds are sold to banks in the risky country. Nonzero losses occur, if and only if

$$
1<\left(1-\frac{\theta}{q}\right) \beta .
$$

With these results, we can finally succinctly state the government's problem.

Proposition 7 The risky government picks $\bar{b}$ as well as $\beta, \theta, g_{2}$, in order to maximize $E\left[g_{2}\right]$, subject to

$$
\begin{aligned}
q & =\max \left\{E[\theta], \frac{g_{0}}{\bar{b}}\right\} \\
\beta & =\frac{q \bar{b}}{n} \\
1 & \leq \chi(\beta) \\
y & =g_{2}+\theta\left(\frac{g_{0}}{q}+\alpha n \max \left\{\left(1-\frac{\theta}{q}\right) \beta-1 ; 0\right\}\right) \\
\theta & \leq 1 \\
0 & =g_{2}(1-\theta) .
\end{aligned}
$$

Proof: This collects equations and conditions from above.

This can be analyzed further as follows. Define

$$
\theta^{*}(q)=q\left(1-\frac{n}{g_{0}}\right)
$$


Note that $\theta^{*}(q)$ is that value for $\theta$, at which the expression for the losses in equation (19) equals zero, in case all bonds are sold to banks in the risky country. Furthermore, define

$$
y^{*}=g_{0}-n .
$$

Proposition 8 Suppose, all bonds are sold to banks in the risky country. Then we have

1. $0<\theta^{*}(q)<1$.

2. The government budget constraint (24) can be rewritten as

$$
y-g_{2}= \begin{cases}\theta\left(\frac{g_{0}}{q}(1-\alpha \theta)+\alpha\left(g_{0}-n\right)\right) & \text { if } \theta \leq \theta^{*}(q) \\ \theta \frac{g_{0}}{q} & \text { if } \theta \geq \theta^{*}(q)\end{cases}
$$

3. The right-hand side of (29) takes the value 0 at $\theta=0$ and the value $B=g_{0} / q$ at $\theta-1$, is continuous and strictly increasing in $\theta \in[0,1]$. It has an upwards-bending kink at $\theta=\theta^{*}(q)$.

4. Given $q$ and for every $y$, there is a unique

$$
\theta=\Theta(y, q) \in[0,1]
$$

and $g_{2}$, solving the government problem of proposition 7 . For $y<B$, the solution is $g_{2}=0$ and $\theta<1$, solving equation (29) at $g_{2}=0$, while $\theta=1$ for $y \geq B$ and $g_{2}=y-g_{0} / q$. Given $q$, expected government consumption is

$$
E\left[g_{2}\right](q)=\int_{y \geq \frac{g_{0}}{q}}\left(y-\frac{g_{0}}{q}\right) G(d y)
$$

5. If $y<y^{*}$, then

$$
\theta=\Theta(y, q)=\frac{1}{2}\left(\frac{1}{\alpha}+\theta^{*}(q)-\sqrt{\left(\frac{1}{\alpha}+\theta^{*}(q)\right)^{2}-4 \frac{y q}{\alpha g_{0}}}\right)
$$


and $\theta<\theta^{*}(q)$ as well as losses in the banking system, $L>0$. If $y^{*} \leq y \leq B=g_{0} / q$, then

$$
\theta=\Theta(y, q)=y \frac{q}{g_{0}},
$$

while the losses are zero, $L=0$.

\section{Proof:}

1. This follows from $n<g_{0}$.

2. This should be clear.

3. The values at $\theta=0$ and $\theta=1$ as well as continuity are easy to verify. Given $q$, define

$$
p(\theta)=\theta\left(\frac{g_{0}}{q}(1-\alpha \theta)+\alpha\left(g_{0}-n\right)\right),
$$

which is a quadratic and concave polynomial in $\theta$. The derivative of $p(\theta)$ is

$$
\begin{aligned}
p^{\prime}(\theta) & =\frac{g_{0}}{q}(1-2 \alpha \theta)+\alpha\left(g_{0}-n\right) \\
& =\frac{g_{0}}{q}(1-\alpha \theta)+\alpha\left(\frac{g_{0}}{q}(q-\theta)-n\right) .
\end{aligned}
$$

Inspecting (19), notice that

$$
0=\frac{g_{0}}{q}\left(q-\theta^{*}(q)\right)-n .
$$

Thus, while $p(\theta)$ may reach its maximum for some $\theta \in(0,1)$, use the second line of (34) and the property (35) or brute-force algebra to calculate that

$$
p^{\prime}\left(\theta^{*}(q)\right)=\frac{g_{0}}{q}\left(1-\alpha \theta^{*}(q)\right)>0 .
$$


Hence, $\theta^{*}(q)$ is to the left of the peak of $p(\theta)$. Furthermore,

$$
p^{\prime}\left(\theta^{*}(q)\right)<\frac{g_{0}}{q}
$$

and $\frac{g_{0}}{q}$ is the derivative of (29) to the right of $\theta^{*}(q)$, delivering the result about the nature of the kink.

4. This is now obvious.

5. Calculate.

If all bonds are sold to banks in the risky country, the expected consumption of a banker there will be

$$
\bar{c}(q)=E\left[\max \left\{\left(\frac{\Theta(y ; q)}{q}-1\right) \frac{g_{0}}{n}+1 ; 0\right\}\right] .
$$

The attractiveness constraint (15) then demands that

$$
1 \leq \bar{c}(q)
$$

Proposition 9 Suppose, all bonds are sold to banks in the risky country. Then,

1. if $\alpha<1$, then the solution to the problem of the government is to choose the maximum value of $q$, such that $\bar{c}(q) \geq 1$.

2. If $\Theta(y ; q)$ is not constant almost surely as a function of $y$ and given $q$, then $q<\sup _{\{y \in \operatorname{supp}(G)\}} \Theta(y ; q)$.

3. $\bar{c}(q)=1$ implies that the expected return $R^{e}$ on investing one unit in the risky government bond satisfies

$$
R^{e}=\frac{E[\Theta(y ; q)]}{q} \leq 1 .
$$


Furthermore, this inequality is strict, if "max" binds with positive probability in (36). In that case, banks in safe countries will not purchase any risky bonds.

\section{Proof:}

1. Note that expected government consumption $E\left[g_{2}\right](q)$ given in equation (30) is an increasing function of $q$. The government will therefore pick the maximum $q$ compatible with the attractiveness condition.

2. If $q \geq \sup _{\{y \in \operatorname{Supp}(G)\}} \Theta(y ; q)$ and thus $q>\Theta(y ; q)$ with positive probability in realizations of $y$, then $\bar{c}(q)<1$, violating the attractiveness condition.

3. Note that

$$
1=\bar{c}(q) \geq\left(E\left[\frac{\Theta(y ; q)}{q}\right]-1\right) \frac{g_{0}}{n}+1,
$$

which can be rewritten as

$$
0 \geq \frac{E[\Theta(y ; q)]}{q}-1
$$

Furthermore, the inequality in (39) is strict, if "max" binds with positive probability in (36).

The second part of the proposition means that, in order to attract the banks to buy the bonds, they have to earn a profit from holding these bonds on occasions, in order to make it worth their while. The proposition now also gives us the key risk shifting insight of this paper, and the insight that bonds of the risky country are held by their home banks, if feasible. Given that the risky government will drive $\bar{c}(n)$ to (just above) unity, it follows that the expected return on investing one unit of resources in the debt of that country 
is below the safe return, if bank insolvencies occur at all in the defaulting country. Since regulators in safe countries would strictly regulate their banks so that no losses are borne by the governments there, the risks are entirely borne by the banks, the expected return is what matters, and they would not invest in the bonds of the risky country.

As for the common central bank and the sovereign default risk shifted onto its balance books, note that its expected losses are given by

$$
E\left[L_{\mathrm{CB}}\right](q)=E\left[(1-\alpha \Theta(y ; q)) \max \left\{0 ;\left((q-\Theta(y ; q)) \frac{g_{0}}{q}-n\right)\right\}\right]
$$

as a function of $q$.

Proposition 10 If $q=E[\theta]$, then $\bar{b}=0$ solves the problem of the risky government, i.e., it is best to sell all bonds to foreign banks ${ }^{5}$. In that case,

$$
\begin{aligned}
\theta & =\min \left\{1 ; \frac{q}{g_{0}} y\right\} \\
g_{2} & =y-\theta \frac{g_{0}}{q}
\end{aligned}
$$

With positive probability, the government will not default, $P(\theta=1)>0$.

Proof: This can be seen by examining (24): the left-hand side is constant or increasing in $\beta$, increasing in $q$ and increasing in $\theta$, noting that $\theta \alpha \beta n / q \leq$ $\theta \alpha g_{0} / q \leq g_{0} / q$. Finally, multiply (24) or

$$
y-g_{2}=\theta \frac{g_{0}}{q}
$$

with $q$ and take expectations to find

$$
E[\theta]\left(E[y]-E\left[g_{2}\right]\right)=E[\theta] g_{0}
$$

or $E\left[g_{2}\right]>0$ due to (1). That, however, can only happen with $P(\theta=1)>0$.

\footnotetext{
${ }^{5}$ I exclude the case $q=0$.
} 
Intuitively, if there is no price gain to be obtained from selling bonds to own-country banks, compared to the actuarily fair value $E[\theta]$, then it is best to get the best possible bond price by not also not risking exposure to bank losses in the second period, since they will be "priced in" by bond holders.

Proposition 11 The complete characterization of the solution to the government problem is as follows.

1. If $g_{0}>n+1$, then all bonds are sold to foreign banks as in proposition 10 .

2. If $g_{0} \leq n+1$, then compare the solution of proposition 9 from selling all bonds to home country banks to the solution from selling all bonds to foreign banks given in proposition 10. Pick the solution, which offers the highest expected government consumption, i.e. the solution with the highest q.

Proof: This follows now from propositions 7, 9 and 10.

\section{Numerical illustrations}

\subsection{A two-point distribution}

For an analytical case, consider a two-point distribution $\left\{y_{L}, y_{H}\right\}$ for $y$, with

$$
0<y_{L}<g_{0}<y_{H}
$$

Let $p_{H}=P\left(y=y_{H}\right), p_{L}=1-p_{H}$ and $0<p_{H}<1$. Suppose that $\alpha=1$, so that the central bank only bears losses in the case that the country defaults. 
Finally, suppose that $n$ is negligible compared to $g_{0}$ : we shall equate it to zero, unless we need to divide by it. Assume that $g_{0}<1$, so that owncountry resources at the home banks (per the initial deposits of households) are sufficient for purchasing all bonds.

Per proposition 11, calculate the solution given in proposition 9, when all bonds are sold to home country banks. With $n=0$, it follows that

$$
\begin{aligned}
y^{*} & =g_{0} \\
\theta^{*}(q) & =q
\end{aligned}
$$

It follows from proposition 8 , that bank losses will occur for $y=y_{L}$, but not for $y=y_{H}$. Furthermore, the government will be in default for $y=y_{L}$ and $g_{2, L}=0$ will be zero in that state. The government budget constraint for $y=y_{H}$ reads

$$
y_{H}=g_{2, H}+\theta_{H} \frac{g_{0}}{q}
$$

and the government will be able to obtain positive consumption $g_{2, H}>0$ for this state only if $\theta_{H}=1$ : we shall thus proceed with the assumption that the government can feasibly choose $\theta_{H}=1$ and verify it. With these results, one can now examine the attractiveness condition 37 , restated as

$$
\begin{aligned}
n & \leq \bar{c}(q) n \\
& =p_{H}\left(\left(\frac{1}{q}-1\right) g_{0}+n\right)
\end{aligned}
$$

or as

$$
q \leq 1
$$

with $n=0$. Thus, the government chooses $q=1$ with the appropriate date- 0 regulation, and consumes

$$
g_{2, H}=y_{H}-g_{0}
$$

in the high income state. It follows from proposition 11, that the government cannot possibly do better than this, since $q \leq 1$. Thus, selling all bonds to 
home country banks is a solution to the government problem. Since the government must necessarily be in default in the $y_{L}$-state, if $q=1$, it also follows that this is the unique solution.

In the low income state, the repayment fraction is given by equation (31) and thus by

$$
\theta_{L}=1-\sqrt{1-\frac{y_{L}}{g_{0}}} .
$$

Note that the expected return on investing one unit of resources in the government bond is given by

$$
R^{e}=1-p_{L} \sqrt{1-\frac{y_{L}}{g_{0}}}<1
$$

and that therefore banks in solvent countries will be regulated to invest in these only at their own peril, and then choose not do so, verifying our initial conjecture. Finally, note that the losses to the common central bank occur due the bankruptcy of the country in the $y=y_{L}$ state. The expected losses are given by (40) and calculate to

$$
\begin{aligned}
E\left[L_{C B}\right](q=1) & =p_{L}\left(1-\theta_{L}\right)^{2} g_{0} \\
& =p_{L}\left(g_{0}-y_{L}\right),
\end{aligned}
$$

since the central bank bears the entire default burden of the difference between the promised repayment $g_{0}$ on the bonds minus the actual repayment $y_{L}$ in the default state.

\section{$3.2 \quad$ A numerical example}

To gain some more insights, it is useful to examine some numerical cases.

Suppose that $\alpha=1, g_{0}=1, n=0.2$ and that $y$ is uniformly distributed on $[\epsilon, 2]$ for some tiny $\epsilon>0$. Note that (1) holds "nearly" with equality, which implies that selling only to foreign banks as in proposition 10 yields a value very close to $q=0.5$, as well as $E\left[g_{2}\right]$ very close to zero. 
When selling only to home banks as in proposition 9 , the numerical calculation yields $q=0.835, E\left[g_{2}\right]=0.163$ and the expected losses to the central bank are $E\left[L_{C B}\right]=0.198$. Since the bond price as well as expected secondperiod consumption of the government is higher than in the solution, when selling only to foreign banks, the government will prefer this solution.

For the equilibrium $q$, figure 2 shows the relation given by the right-hand side of equation (29) between the default rate $\theta$ and the income $y$. Notice how the relationship first follows a quadratic, when taking into account the losses to insolvent banks, and then follows a linear relationship, when banks remain solvent.

For the equilibrium $q$, figure 3 flips the relationship shown in (2) and shows the solution for $\theta$, given the income realization $y$. Notice how the solution first follows the square root law of equation (31) and then follows a linear relationship for $y \geq y^{*}$, until reaching the full repayment point $\theta=1$.

In figure 4 , the dashed line shows $\bar{c}(q)$, while the solid line starting at zero and then sloping upwards near $q=0.6$ shows $E\left[g_{2}\right](q)$. The government chooses $q$ as high as possible, subject to the attractiveness constraint, i.e., subject to the constraint that the dashed line is just above unity, indicated by the horizontal solid line.

The expected losses to the common central bank as a function of $q$ are shown in figure 5. They are increasing with $q$, since higher $q$ means larger losses in the default states.

Judged entirely from the perspective of the expected losses, the common central bank would prefer the country to regulate the banks such that a lower $q$ results: this makes the banks more profitable, induces fewer losses on the central bank, but implies lower expected consumption for the risky country in the second period. 


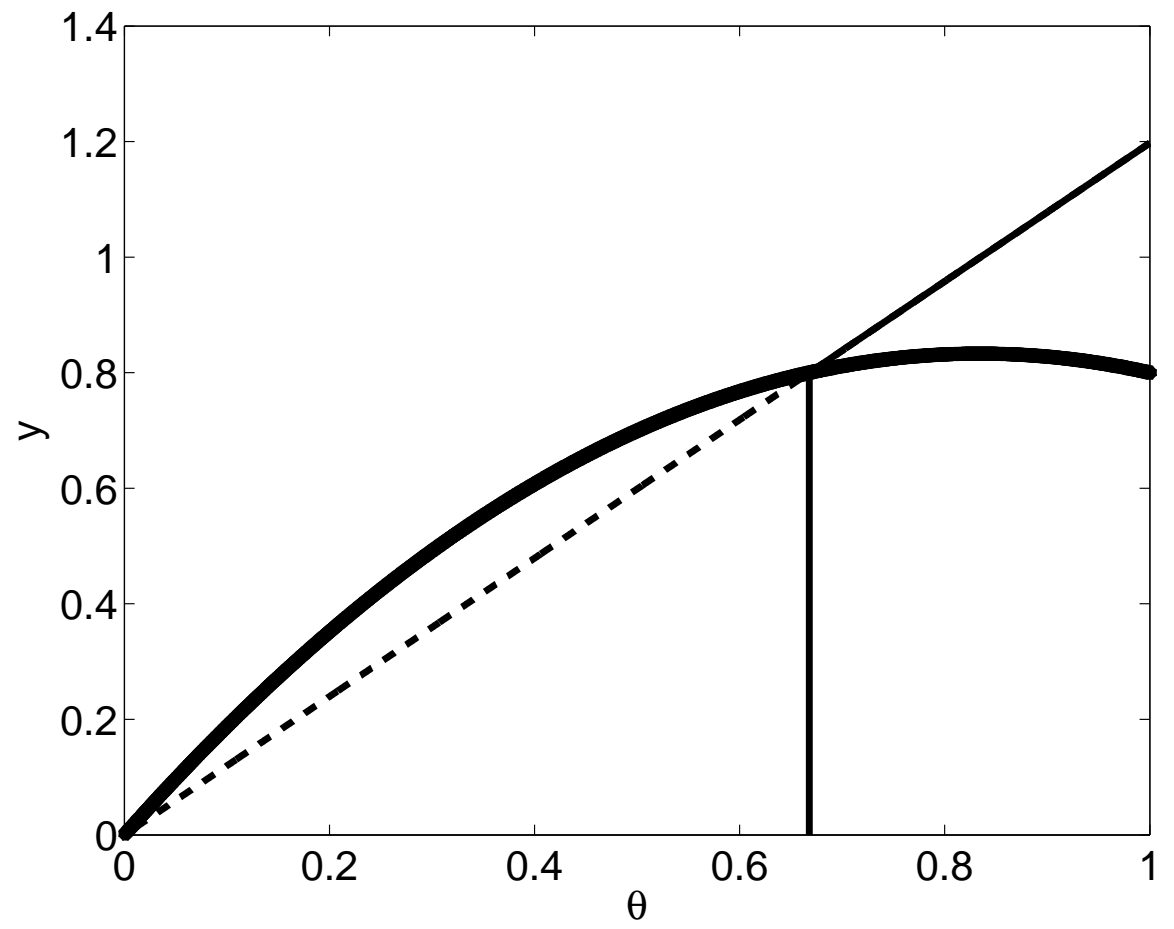

Figure 2: For the equilibrium q, this figure shows the relation given by the right-hand side of equation (29) between the default rate $\theta$ and the income y. Notice how the relationship first follows a quadratic, when taking into account the losses to insolvent banks, and then follows a linear relationship, when banks remain solvent. 


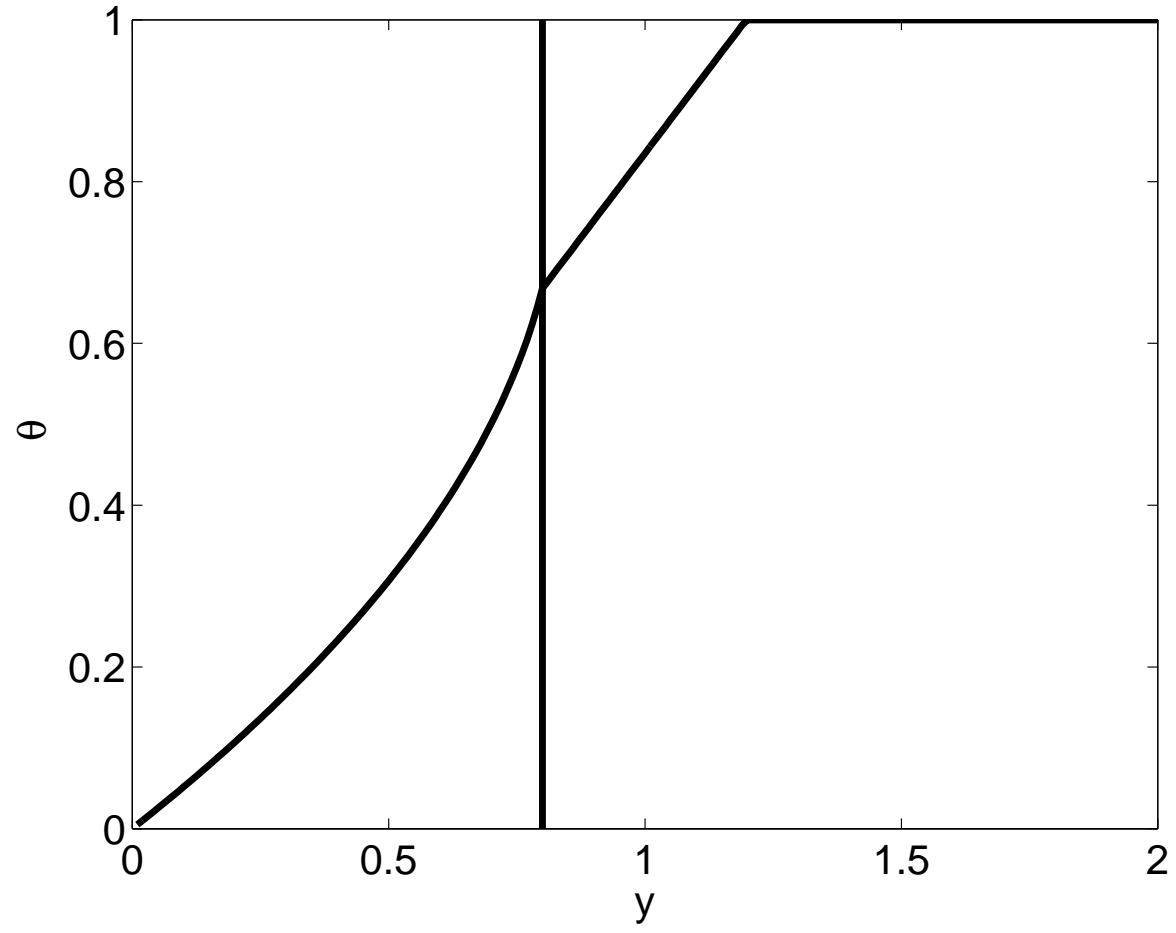

Figure 3: For the equilibrium q, this figure flips the relationship shown in (2) and shows the solution for $\theta$, given the income realization $y$. Notice how the solution first follows the square root law of equation (31) and then follows a linear relationship for $y \geq y^{*}$, until reaching the full repayment point $\theta=1$. 


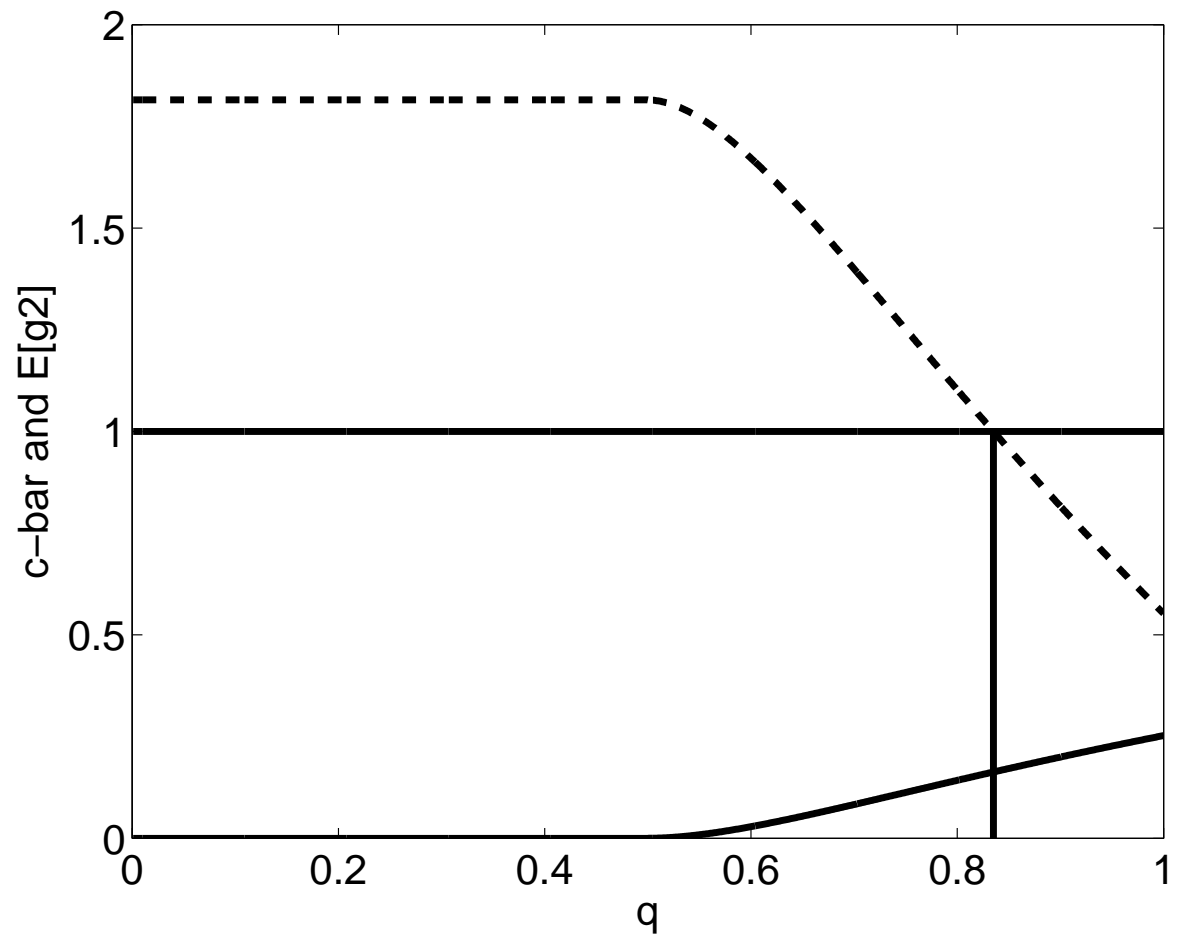

Figure 4: The dashed line shows $\bar{c}(q)$, while the solid line starting at zero and then sloping upwards near $q=0.6$ shows $E\left[g_{2}\right](q)$. The government chooses $q$ as high as possible, subject to the attractiveness constraint, i.e., subject to the constraint that the dashed line is just above unity, indicated by a horizontal solid line. 


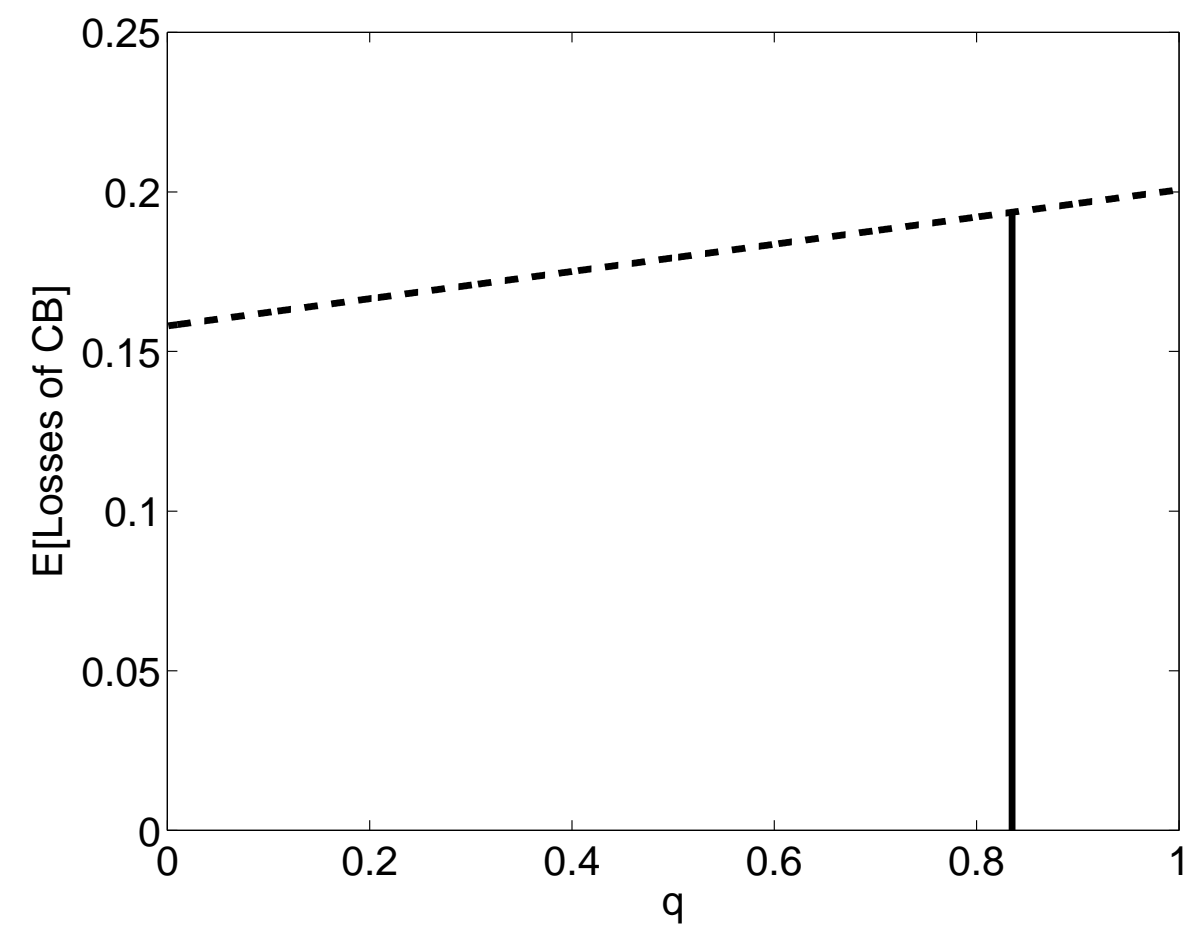

Figure 5: The expected losses to the common central bank as a function of $q$ are shown: they are increasing with $q$, since higher q means larger losses in the default states. 


\section{Conclusions}

This paper seeks to understand the interplay between banks, bank regulation, sovereign default risk and central bank guarantees in a monetary union. The empirical literature has documented an increasing exposure and shift towards home sovereign bonds, in particular in troubled countries in the Euro zone during the Euro zone crisis. It has found support for the risk-shifting hypothesis, i.e., that these portfolio strategies enable banks and sovereign regulators to shift some of the sovereign default risks onto the common central bank. The paper at hand has provided a model of these developments. I assume that risk neutral bankers can use sovereign bonds for repurchase agreements with a common central bank, and that their sovereign partially backs up any losses, should the banks not be able to repurchase the bonds. I argued that regulators in risky countries have an incentive to allow their banks to hold home risky bonds and risk defaults, while regulators in other "safe" countries will impose tighter regulation, and indeed, regulate their banks such that all losses have to be borne privately. Consequently, banks in safe countries will hold these bonds only if their price is at least actuarily fair, while banks in the risky country may be allowed by their regulators to risk defaults, since these defaults happen precisely when the country is in default itself, and therefore no longer can and will pay for their share of the bank losses. As a result, governments in risky countries get to borrow more cheaply, effectively shifting some of the potential sovereign default losses on the common central bank. I have analyzed the interplay between the various agencies, and illustrated the result with a numerical example. 


\section{References}

[1] Acharya, Viral V. and Sascha Steffen (2013), "The 'Greatest' Carry Trade Ever? Understanding Eurozone Bank Risks," CEPR Discussion Paper No. 9432.

[2] Broner, Fernando, Aitor Erce, Alberto Martin and Jaume Ventura (2013), "Sovereign Debt Markets in Turbulent times: Creditor Discrimination and Crowding-Out Effects," draft, CREI and UPF, Barcelona.

[3] Claessens, Stijn and M. Ayhan Kose (2013), "Financial Crises: Explanations, Types, and Implications," IMF WP/13/28.

[4] Corradin, Stefano and Maria Rodriguez-Moreno (2013), "Limits to arbitrage: empirical evidence from Euro are sovereign bond markets," draft, European Central Bank.

[5] Drechsler, Itamar, Thomas Drechsel, David Marques-Ibanez and Philipp Schnabel (2013), "Who Borrows from the Lender of Last Resort?", draft, NYU-Stern and ECB.

[6] Reinhart, Carmen (2012a), "A Series of Unfortunate Events: Common Sequencing Patterns in Financial Crises," NBER WP 17941, Boston, MA.

[7] Reinhart, Carmen (2012b), "The Return of Financial Repression," CEPR Discussion Papers 8947, C.E.P.R. Discussion Papers, London.

[8] Roch, Francisco and Harald Uhlig (2012), "The Dynamics of Sovereign Debt Crises and Bailouts", draft, University of Chicago.

[9] Sinn, Hans-Werner (2012), Die Target Falle: Gefahren für unser Geld und unsere Kinder, Carl Hanser Verlag, Munich, Germany. 